\title{
Incident Reporting and its Implications for Patient Safety
}

\section{Bill Runciman *}

Although awareness of the possibility of healthcare harming those for whom a reduction in illness and suffering is intended goes back to the dawn of civilisation (the Code of Hammurabi and the Hippocratic aphorism "first, do no harm"), the modern patient safety movement started less than 40 years ago, and only gained momentum at the turn of the century.

Things that go wrong in healthcare are characterised by being made up of a relatively small number of categories that account for about $20 \%$ of the problems, and then a very large number of categories would make up $80 \%$. Each of these are encountered only rarely. This situation means that classical prospective quantitative research methodology cannot be used for the bulk of the things that go wrong. Moreover, clinicians are taught as students not to implicate the system or their colleagues when things go wrong, so little can be leaned about the underlying causes of the problems from medical records.

Instead we are left either with real time studies (observation and interviews) which are valuable but expensive, or collecting information about what happened after things have gone wrong. Systems available to do this include incident reporting, complaints, medico legal files, and coronial recommendations. The evolution of the methods available to collect and analyse this information will be traced, and the information that has been learnt will be summarised, and an account of the International Classification for Patient Safety and its development will be given. Some suggestions will be made as to how systems might best be set up and used in the future.

\footnotetext{
* Prof.Bill Runciman, Professor of Patient Safety, University of South Australia

President, Australian Patient Safety Foundation.
} 